\title{
Atomization performance of effervescent atomizers with gas-liquid internal mixing
}

\author{
Marek Ochowiak, Lubomira Broniarz-Press \\ ${ }^{1}$ Poznan University of Technology, Department of Chemical Engineering and Equipment, Pl. M. Sklodowskiej-Curie 2, \\ 60-965 Poznań, Poland, e-mail: Marek.Ochowiak@put.poznan.pl
}

\begin{abstract}
The paper contains the results of experimental studies on water atomization process in effervescent nozzle in one-phase and two-phase systems. The gas phase flow rate causes the changes in characteristic parameters of atomization. The gas flow rate has certain effect on the Sauter Mean Diameter SMD values. SMD for airliquid systems investigated is decreasing with increase of gas volume rate. It is observed that SMD values are increasing with increase of liquid volume rate. The larger SMD values for one-phase flow in comparison with two-phase flow have also been observed. The increase of SMD value has been observed with a decrease of an outlet diameter of an effervescent nozzle.
\end{abstract}

Keywords: effervescent atomizer, atomization, spray formation, two-phase system.

\section{INTRODUCTION}

Effervescent atomization is a method of twin-fluid atomization that involves bubbling a small amount of gas into the liquid before it is ejected from the atomizer. The technique of bubbling gas directly into the liquid stream inside the atomizer body is essentially different from other methods of twin-fluid atomization (either internal or external mixing) and leads to significant improvements in performance in terms of smaller drop sizes and/or lower injection pressures. The effervescent nozzles fall into the category of internal mixing nozzles. Atomizing gas is injected into the liquid at very low velocity to form a bubbly two-phase mixture upstream of the discharge orifice. This method of atomization is not restricted to volatile liquids or liquids that can hold a substantial amount of dissolved gas. Neither is the choice of gas restricted to those that can dissolve readily into the liquid. Furthermore, the bubble formation process does not involve mass diffusion of dissolved gas to the nucleation sites, as in dissolved gas atomization, or energy diffusion necessary for evaporation, as in flash atomization. These inherently slow processes necessitate the use of expansion chambers in flashing and dissolved gas systems, limitations not found in effervescent atomizers. Effervescent atomizers have so far been found useful for gas turbine fuel injectors, for internal combustion engines and for consumer product sprays. Atomization of liquids is a core element in many chemical engineering processes such as in agglomeration, spray drying, and spray painting ${ }^{1-6}$. The effervescent atomizer with gas-liquid internal mixing offers several advantages over conventional types such as equivalent droplet sizes at reduced atomizing gas consumption, compared to what is obtained with pneumatic atomizers, and the reduced clogging as the result of a construction of nozzle ${ }^{7-9}$.

The paper contains the results of experimental investigation of atomization process in effervescent nozzles with internal mixing obtained by the use of the digital microphotography method.

\section{EXPERIMENTS AND RESULTS}

The schematic diagram of experimental apparatus is shown in Fig. $1^{7}$. The nozzles consist of four main components: liquid and gas supply ports, a mixing chamber where the gas
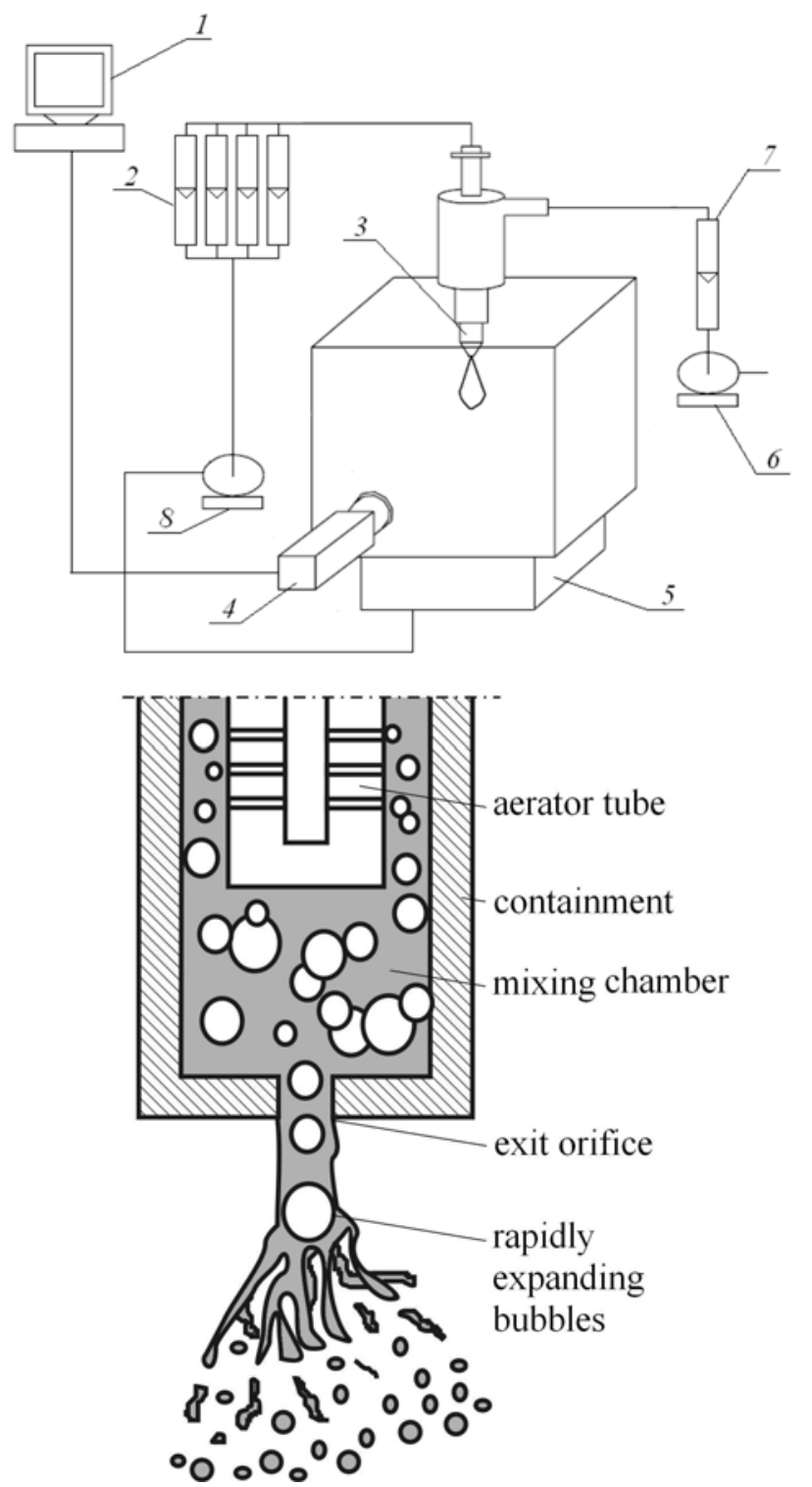

Figure 1. Test installation and scheme of the atomization mechanism: 1 - PC computer, 2 - liquid rotameters, 3 - nozzle, 4 - digital camera, 5 - vessel, 6 - blower, 7 - gas rotameter, 8 - pump 
is bubbled into the liquid stream, and an exit orifice. The nozzles used in this study have a diameter of outlet $\left(d_{o}\right) 2$, 3 , and $4[\mathrm{~mm}]$. The multi-hole aerator (aerator tube diameter $\mathrm{d}_{\mathrm{A}}$ of $15 \mathrm{~mm}$ ) has 20 holes of diameter $\mathrm{d}_{\mathrm{h}}$ of $1 \mathrm{~mm}$. The photographs have been obtained using a Canon 1D Mark III camera with exposure time of 1/8000 s. The photographs were analyzed using Image Pro-Plus delivered by Media Cybernetics. The observations were carried out at liquid flow rate $\left(\mathrm{V}_{\mathrm{L}}\right)$ values changed from 0.0014 to $0.011\left[\mathrm{dm}^{3} / \mathrm{s}\right]$ and gas flow rate $\left(\mathrm{V}_{\mathrm{G}}\right)$ from 0.14 to $0.7\left[\mathrm{dm}^{3} / \mathrm{s}\right]$.

The analysis of photos (Figs. 2 - 3) shows that the droplets which have been formed during the liquid atomization have very different sizes. The smallest droplets have diameters of the order of ten micrometers. The differences between characteristics of water atomization for one phase and two-phase flows in effervescent nozzle have been observed too. The atomization mechanism in effervescent nozzles was described in detail by Roesler and Lefebvre ${ }^{\mathbf{1 0}-\mathbf{1 1}}$.

Sauter mean diameter (SMD) is calculated as the ratio:

$\mathrm{SMD}=\frac{\sum_{\mathrm{i}} \mathrm{n}_{\mathrm{i}} \mathrm{d}_{\mathrm{i}}^{3}}{\sum \mathrm{n}_{\mathrm{i}} \mathrm{d}_{\mathrm{i}}^{2}}$

In Fig. 4 the relations between SMD and liquid and gas volume rates for different outlet diameters are shown. The gas flow rate has certain effect on the SMD values. SMD for air-liquid systems investigated is decreasing with increase of gas volume rate. It is observed that, SMD values are increasing with increase of liquid volume rate. The larger SMD values for one-phase flow in comparison with two-phase flow have been observed too. The increase of SMD value with decrease of outlet diameter is typical for investigated nozzle geometries. The atomizing gas-to-liquid ratio by mass (GLR) is an important operating parameter in most applications since it is desirable to minimize the amount of atomizing gas supplied while maintaining a small mean drop size.

The influence of GLR on SMD is illustrated in Fig. 5. The experimental results show that SMD is a non-linear function of GLR, with mean drop size decreasing rapidly as GLR is increased from zero to around 0.05 and thereafter decreasing at a slower rate with further increase in GLR. Our studies have shown that at low GLRs $(<0.05)$, atomizers with low values of the ratio of the final discharge orifice area to the total area of the aerator holes $\left(\mathrm{A}_{\mathrm{o}} / \mathrm{A}_{\mathrm{h}}\right)\left(0.2\right.$ for $\left.\mathrm{d}_{\mathrm{o}}=2 \mathrm{~mm}\right)$ produced finer sprays than those produced by atomizers with high values of $A_{o} / A_{h}\left(0.45\right.$ for $d_{o}=3 \mathrm{~mm}$ and 0.8 for $\left.\mathrm{d}_{\mathrm{o}}=4 \mathrm{~mm}\right)$. In all cases GLR played a key role in the mean droplet size. The low air consumption may have an important influence in processes where the air consumption has to be limited due to product characteristics.

\section{CONCLUSIONS}

This work confirms previous reports that changes in both, geometry of spray atomizer and character of flow (one- or two-phase flow, gas and liquid flow rates) can lead to significant changes in the quality of the spray produced by effervescent atomizers. The SMD values for air-liquid systems investigated are decreasing with increase of gas volume rate. It is observed that, SMD values are increasing with increase of liquid volume rate. The larger SMD values for one-phase flow in comparison with two-phase flow have been observed too. In all cases GLR played a key role in the mean droplet size. a)

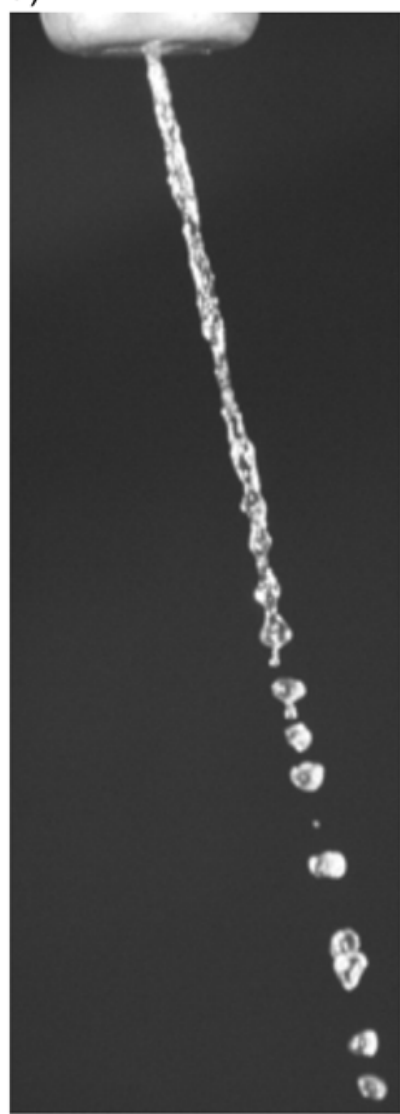

b)

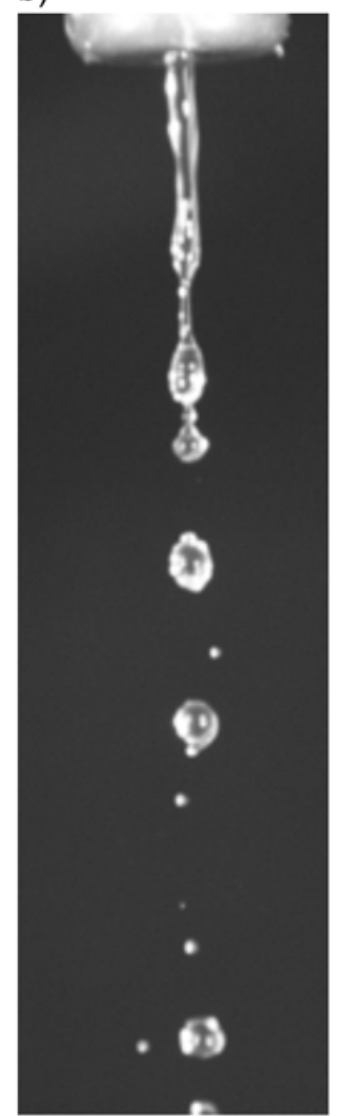

c)

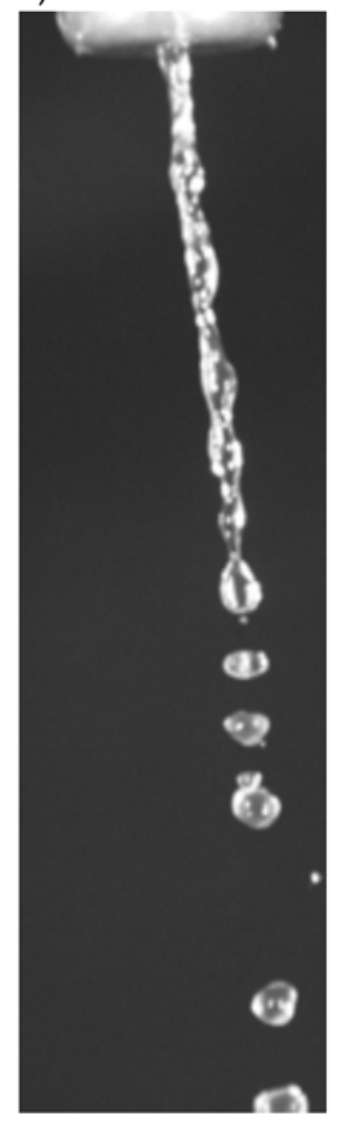

d)

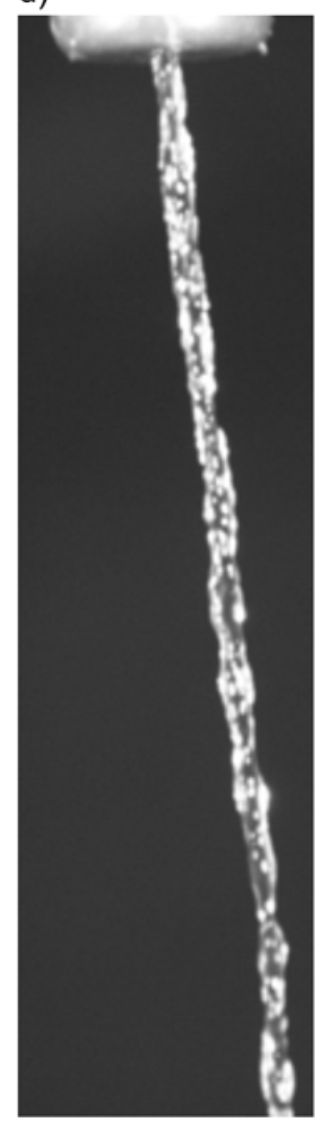

e)

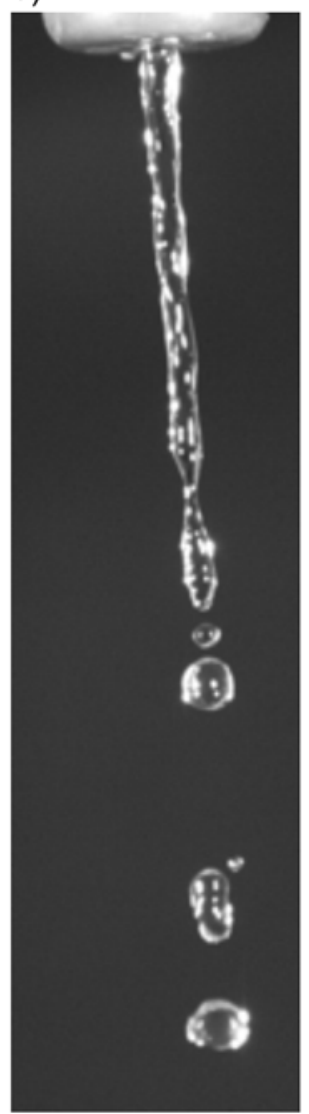

Figure 2. One-phase flow: a) $\left.\left.d_{o}=2 \mathrm{~mm}, V_{L}=0.0055\left[\mathrm{dm}^{3} / \mathrm{s}\right] ; b\right) d_{o}=3 \mathrm{~mm}, V_{L}=0.0028\left[\mathrm{dm}^{3} / \mathrm{s}\right] ; c\right) d_{o}=3 \mathrm{~mm}$, $\left.\left.\mathrm{V}_{\mathrm{L}}=0.0055\left[\mathrm{dm}^{3} / \mathrm{s}\right] ; \mathrm{d}\right) \mathrm{d}_{\mathrm{o}}=3 \mathrm{~mm}, \mathrm{~V}_{\mathrm{L}}=0.011\left[\mathrm{dm}^{3} / \mathrm{s}\right] ; \mathrm{e}\right) \mathrm{d}_{\mathrm{o}}=4 \mathrm{~mm}, \mathrm{~V}_{\mathrm{L}}=0.0055\left[\mathrm{dm}^{3} / \mathrm{s}\right]$ 
a)

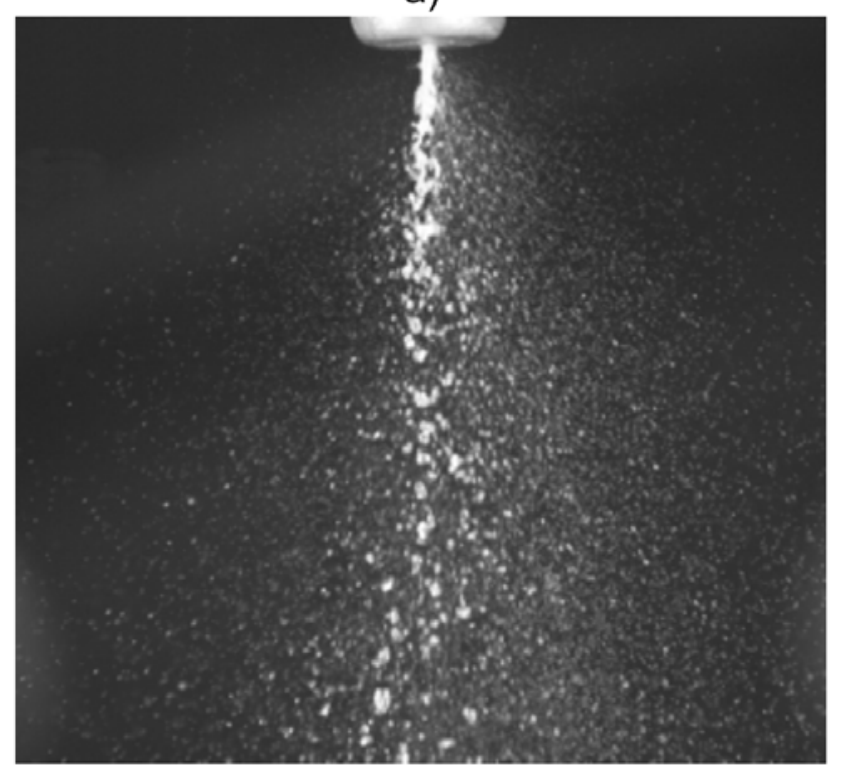

c)

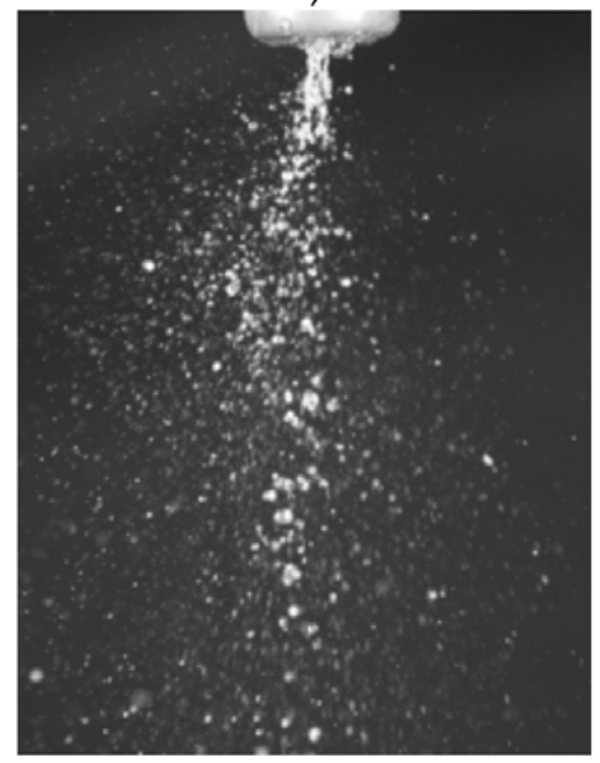

b)

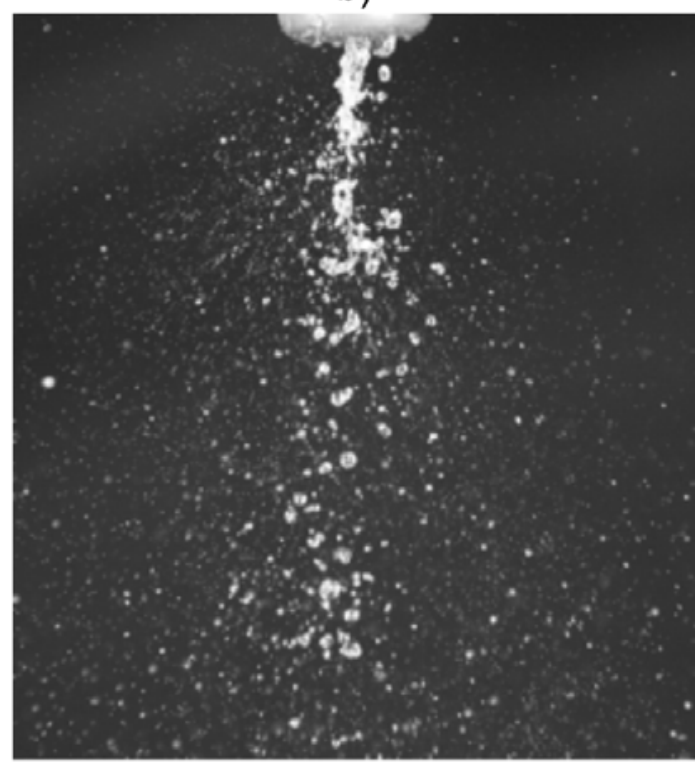

d)

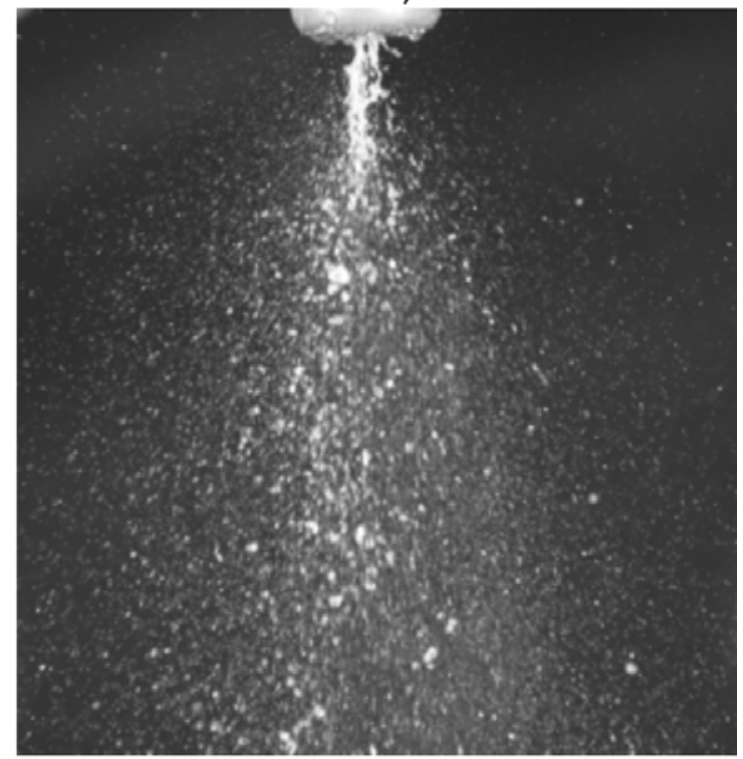

e)

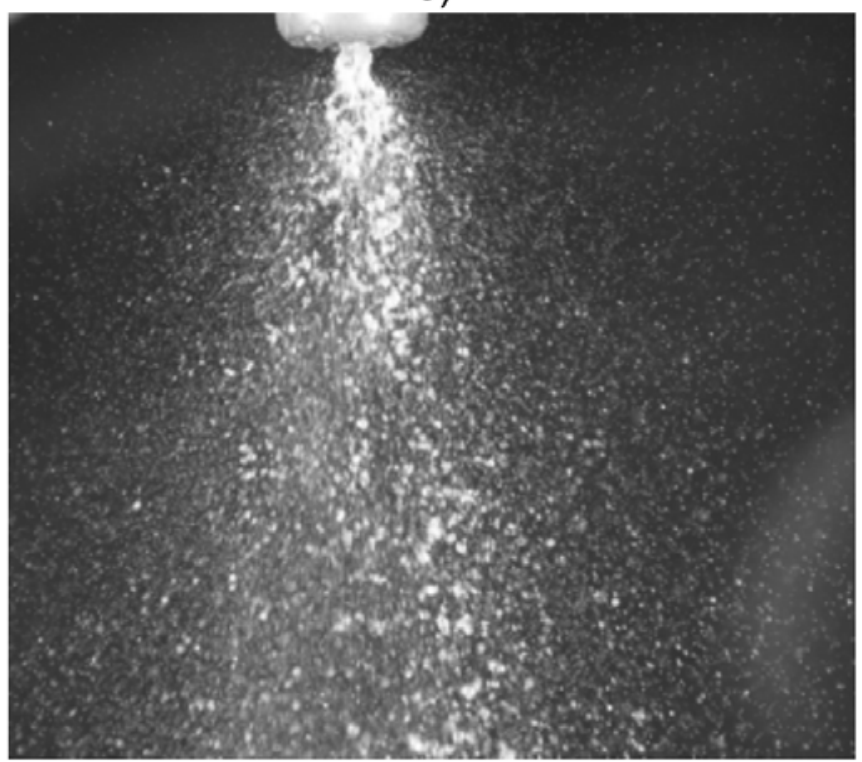

Figure 3. Two-phase flow: a) $d_{o}=2 \mathrm{~mm}, V_{L}=0.0055\left[\mathrm{dm}^{3} / \mathrm{s}\right], V_{G}=0.28\left[\mathrm{dm}^{3} / \mathrm{s}\right] ;$ b) $d_{o}=4 \mathrm{~mm}, V_{L}=0.0055\left[\mathrm{dm}_{3} / \mathrm{s}\right]$, $\left.\left.\mathrm{V}_{\mathrm{G}}=0.28\left[\mathrm{dm}^{3} / \mathrm{s}\right] ; \mathrm{c}\right) \mathrm{d}_{\mathrm{o}}=4 \mathrm{~mm}, \mathrm{~V}_{\mathrm{L}}=0.0028\left[\mathrm{dm}^{3} / \mathrm{s}\right], \mathrm{V}_{\mathrm{G}}=0.56\left[\mathrm{dm}^{3} / \mathrm{s}\right] ; \mathrm{d}\right) \mathrm{d}_{\mathrm{o}}=4 \mathrm{~mm}, \mathrm{~V}_{\mathrm{L}}=0.0055\left[\mathrm{dm}^{3} / \mathrm{s}\right]$, $\mathrm{V}_{\mathrm{G}}=0.56\left[\mathrm{dm}^{3} / \mathrm{s}\right] ;$ e) $\mathrm{d}_{\mathrm{o}}=4 \mathrm{~mm}, \mathrm{~V}_{\mathrm{L}}=0.011\left[\mathrm{dm}^{3} / \mathrm{s}\right], \mathrm{V}_{\mathrm{G}}=0.56\left[\mathrm{dm}^{3} / \mathrm{s}\right]$ 


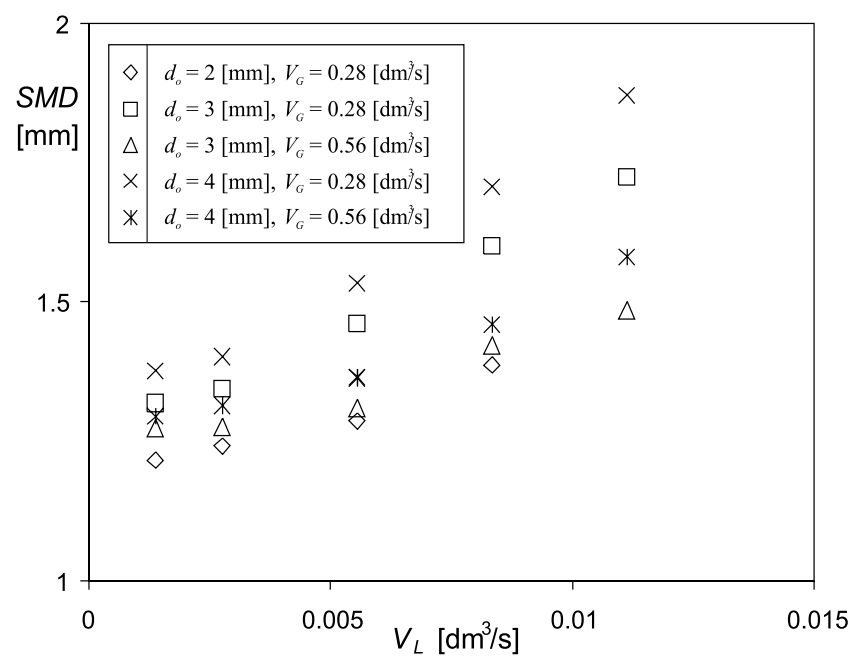

Figure 4. $\mathrm{SMD}$ vs. $\mathrm{V}_{\mathrm{L}}, \mathrm{V}_{\mathrm{G}}$ and nozzle geometry

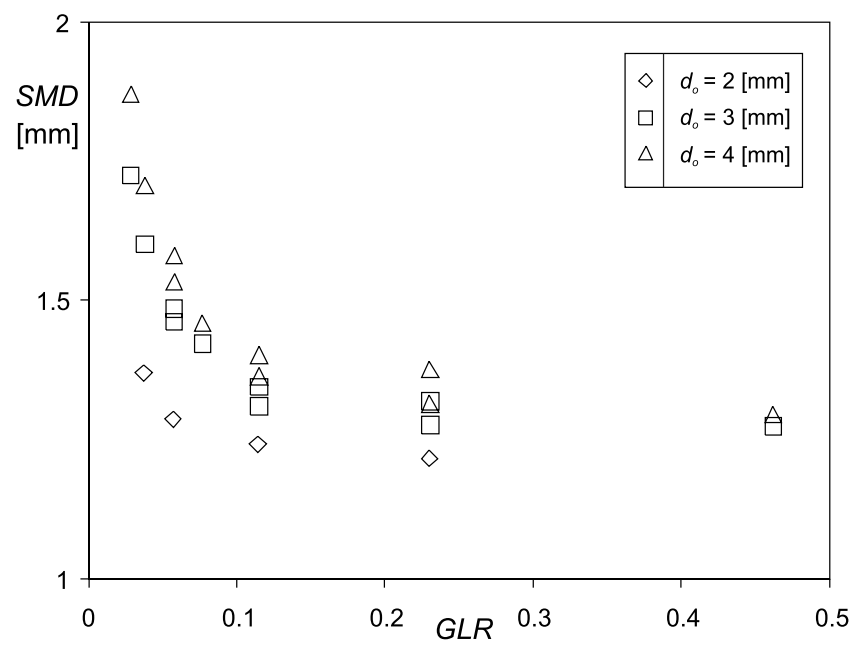

Figure 5. SMD vs. GLR for the atomizers tested

\section{ACKNOWLEDGEMENT}

This research was supported from the Polish Ministry of Science and Higher Education through grant PUT DS ICT $32 / 113$

\section{LITERATURE CITED}

1. Sovani, S.D., Sojka, P.E. \& Lefebvre, A.H. (2001). Effervescent atomization. Prog. Energy Comb. Sci. 27, 483 - 521.

2. Sutherland, J.J., Sojka, P.E. \& Plesniak, M.W. (1997). Entrainment by ligament-controlled effervescent atomizerproduced sprays. Int. J. Multiphase Flow 23(5), 865 - 884.

3. Lefebvre, A.H. (1996). Some recent developments in twin-fluid atomization. Part. Part. Syst. Charact. 13, $205-216$.

4. Jicha, M., Jedelsky, J., Otahal, J. \& Slama, J. (2002). Influence of some geometrical parameters on the characteristics of effervescent atomization, ILASS-Europe, 9-11 September 2002. Zaragoza, Spain.

5. Smith, M.W. (1995). Utilization of effervescent spray technology to eliminate volatile and toxic diluents. Low- and No-Voc Coating Technologies: $2^{\text {nd }}$ Bienniale International Conference, 13-15 March 1995. Durham, North California, U.S.

6. Petersen, F.J., Worts, O., Schaefer, T. \& Sojka, P.E. (2004). Design and atomization properties for an inside-out type effervescent atomizer. Drug Dev. Ind. Pharm. 30(3), 319 $-326$.

7. Broniarz-Press, L., Dulska, D., Ochowiak, M., Rozanski, J., Szaferski, W. \& Woziwodzki, S. (2007). Analysis of wateroil emulsion atomization. Inz. Ap. Chem., 46, 13-14.
8. Ochowiak, M. \& Broniarz-Press, L. (2007). Visualization and analysis of emulsions atomization. VDI Fortschr. Ber. Reihe 3, 883, 183 - 194.

9. Ochowiak, M. \& Broniarz-Press, L. (2008). Atomization of water by one- and two-phase flow through a effervescent nozzles. $18^{\text {th }}$ International Congress of Chemical and Process Engineering CHISA, 24-28 August 2008. Prague, Czech Republic.

10. Roesler, T.C. (1988). An experimental study of aerated liquid atomization, Ph.D. Thesis, Purdue University, U.S., according to [1].

11. Roesler, T.C. \& Lefebvre, AH. (1988). Photographic studies on aerated liquid atomization, combustion fundamentals and applications. Proceedings of the Meeting of the Central States Section of the Combustion Institute, April 1988 (Paper 3). Indianapolis, U.S., according to [1]. 